\title{
Fatores que contribuem ao sucesso ou fracasso em projetos: uma abordagem qualitativa
}

\section{Factors that contribute to project success or project failure: a qualitative approach}

\author{
RONALDO GOMES DULTRA-DE-LIMA* \\ YEN-TSANG CHEN** \\ JOSÉ CARLOS TIOMATSU OYADOMARI*** \\ JOSÉ RICARDO BAPTISTA****
}

\section{RESUMO}

O objetivo do trabalho é investigar quais os fatores que contribuem ao sucesso de projetos gerenciados pela Metodologia da Corrente Crítica (CCPM) e Guia $P M B O K^{\oplus}$. Esta é uma pesquisa qualitativa de caráter exploratório na qual foram conduzidas entrevistas junto a executivos da área de gestão de projetos de empresas nos setores de: energia e automação, tecnologia da informação e aeroespacial, que adotam em suas avaliações a CCPM e Guia $P M B O K^{\circledR}$ adaptado como metodologias de gerenciamento de projetos. Os resultados indicam que os principais fatores que mais influenciam o sucesso em projetos são: o planejamento, habilidades gerenciais, atitudes dos colaboradores, tecnologias e ferramentas, e treinamento na nova metodologia. Por outro lado, os fatores que mais contribuíram ao fracasso de projetos foram duas: o não envolvimento da alta administração e dos stakeholders. Palavras-chave: Gestão de Projetos, Desempenho em Projetos, Sucesso e Fracasso em Projetos, Corrente Crítica, $P M B O K^{\circledR}$.

\footnotetext{
* Universidade Presbiteriana Mackenzie (UPM). ronaldo.lima@mackenzie.br

** Doutor em Administração de Empresas pela EAESP/FGV e Professor vinculado à Neoma Business School. yen-tsang.chen@neoma-bs.fr

*** Universidade Presbiteriana Mackenzie. oyadomari@mackenzie.br

**** Universidade Presbiteriana Mackenzie. josericardo.baptista@mackenzie.br
} 


\section{Abstract}

The objective of this work is to investigate which variables contribute to the project success managed by the critical chain project methodology (CCPM) and the PMBOK® Guide. This is an exploratory qualitative research by which interviews were conducted with executives from project management area in the sectors of the energy and automation, information technology, and aerospace, which adopt in their assessments the CCPM and $\mathrm{PMBOK} \circledast$ Guide adapted as methodologies of project management. The results suggested that the main variables that influence the project success are planning, management skills, employee attitudes, technologies and tools, and training in the new methodology. On the other hand, the most critical variables that contribute to the project failure were the non-involvement of senior management and the stakeholders.

Keywords: Project Management, Performance, Project Success and Failure, Critical Chain, PMBOK.

\section{INTRODUÇÃo}

Tendo em vista que os projetos assumem um papel fundamental na empresa e estejam em consonância com objetivos estratégicos (PIYUSH; DANGAYACH; MITTAL, 2011), é de se esperar que possam ser suportados pela Teoria Baseada em Recursos (TBR). Sob essa teoria, uma empresa adquire uma vantagem competitiva à medida que coloca em prática uma estratégia única, imperfeitamente imitável e imperfeitamente substituível baseada nos seus recursos internos (BARNEY, 1991, 2001; HELFAT; PETERAF, 2003; WERNERFELT, 1984). Considerando o aspecto estratégico, os projetos são os meios pelos quais as empresas lançam novos produtos, implementam suas estratégias, lançam novos empreendimentos, ou melhoram os produtos atuais (BOUER; CARVALHO, 2005; DINSMORE; COOKE-DAVIES, 2006; MARQUES JUNIOR; PLONSKI, 2011; PIYUSH; DANGAYACH; MITTAL, 2011). Devido a essa importância estratégica, os projetos devem ser gerenciados de forma eficiente e eficaz, porém, a literatura é bastante consistente em abordar problemas em projetos. Marques Junior e Plonski (2011) fizeram uma análise bibliométrica e constataram que apenas $28 \%$ dos projetos implementados em tecnologia de informação obtiveram o sucesso 
esperado e $85 \%$ dos projetos não conseguiram cumprir os prazos e orçamentos previamente definidos. Isso também é constatado por instituto de pesquisa americano independente que mostrou que $24,0 \%$ dos projetos em termos mundiais foram cancelados antes de serem completados, $63,0 \%$ não terminaram no prazo e $45,0 \%$ ultrapassaram o orçamento inicial (THE STANDISH GROUP, 2001, 2009). Diante desses números negativos, Stratton (2009) afirma que há muito que se fazer no desenvolvimento de teorias para área de gerenciamento de projetos, embora tenha observado algumas evoluções. Os guias de conhecimento utilizados nessa disciplina são essencialmente normativos e carecem de uma teoria de suporte (JUGDEV, 2004).

Uma questão fundamental que se coloca é porque tantos projetos apresentam problemas técnicos que elevam os custos, prazos, alteram o escopo, e não atendem aos requisitos definidos pelos clientes? A literatura é farta em relatar casos mal sucedidos em gestão de projetos. Shepherd, Patzelt, e Wolfe (2011) consideram que o fracasso em projetos está atrelado ao encerramento de uma iniciativa visando gerar valor à organização, mas que não atendeu as expectativas. Blackstone Jr, Cox III, e Schleier Jr (2009), Levasseur (2010) e Keil e Mähring (2010) também consideram que o fracasso em projetos possa ter uma relação com alguns fatores importantes como: o não envolvimento dos stakeholders nas fases iniciais de implementação, ou aspectos relacionados às competências dos gerentes de projetos como liderança e comunicação, falta de apoio da alta gerência, e a definição de requisitos insuficientes. Esses fatores se negligenciados geram impactos negativos em projetos. Por outro lado, Serrador, Gemino e Reich (2018) ainda complementam que ter uma equipe dedicada visando o atendimento dos stakeholders, orçamento e prazos são fatores fundamentais. Os autores ainda sugerem que os patrocinadores devem estabelecer as metas de orçamento para melhorarem a chances de sucesso do projeto. É notória a falta de um gerenciamento mais eficiente e eficaz que mitigue esses problemas técnicos e estruturais.

A partir de 2001, as empresa de manufatura começaram a avaliar novos métodos de gestão de projetos visando melhorar seu desempenho (KENDRA; TAPLIN, 2004). Essas empresas focaram 
nas capabilities em gestão de projetos baseadas nas competências do gerente do projeto, novas métricas para avaliar o desempenho individual, processo de negócio, estrutura da organização por projeto e práticas gerenciais. No entanto, dado que a literatura de projetos ainda se encontra em sua infância, a definição dos construtos "sucesso em projeto" ou "fracasso em projeto" ainda carece de melhor conceituação (IKA, 2009; PINTO; SLEVIN, 1988; SHAO; MÜLLER; TURNER, 2012). Ika (2009) afirma que há um campo fértil de pesquisa visando essa definição e que isto representa enormes desafios aos pesquisadores.

A literatura ainda apresenta definições ambíguas do construto "sucesso em projeto", pois o conceito é multidimensional no qual o gerenciamento visa atingir as questões mais técnicas e resultados auferidos (IKA, 2009). Quanto ao gerenciamento, o sucesso reside na concepção de que as dimensões mais comuns como custo, prazos e qualidade devem ser atingidas (IKA, 2009; MAHANEY; LEDERER, 2011; SHAO, MÜLLER; TURNER, 2012). Porém, isso não garante que o produto ou serviço decorrente do projeto seja considerado um sucesso de vendas e/ou atinja as expectativas. Por outro lado, há situações nas quais essas dimensões não foram atingidas, mas os resultados provenientes foram surpreendentes (De Wit, 1988; Pinto \& Slevin, 1988).

Diante dos problemas discutidos na literatura, uma nova metodologia de gestão de projetos foi concebida por Eliyahu Goldratt denominada de Corrente Crítica (Critical Chain Project Management - CCPM) e tem chamado atenção de acadêmicos e profissionais da área. As pesquisas na área demonstraram que em 95\% dos projetos que usaram a CCPM corretamente conseguiram respeitar prazos e orçamentos definidos (BALDERSTONE; MABIN, 1998; MABIN ; BALDERSTONE, 2003). Leach (1999) também ratifica que o gerenciamento de projetos baseado na CCPM proporciona um avanço substancial em melhoramento contínuo em relação ao $P M B O K \circledR$. Segundo ele, isso deriva da aplicação da Teoria da Restrição e das Teorias Estatísticas ao gerenciamento de projetos.

Diante dos relatos acima, a questão principal deste trabalho é investigar quais são os fatores que influenciam o sucesso ou fracasso em projetos baseando-se nas aplicações da CCPM e PMBOK®? A 
resposta a essa questão ainda carece de investigação na literatura, pois ainda não há consenso quanto à definição dos construtos (IKA, 2009; PINTO; SLEVIN, 1988; SHAO, MÜLLER; TURNER, 2012). Os resultados desse estudo podem ajudar a entender ou minimizar esse gap na literatura.

A seguir, o presente trabalho está estruturado da seguinte forma: na parte dois apresentamos o referencial teórico abordando a Teoria Baseada em Recursos (TBR) como teoria de suporte, os construtos "Fracasso em projetos" e "Sucesso em projetos", e metodologias de gerenciamento de projetos (CCPM e PMBOK®); na parte três discutimos a metodologia; na parte quatro apresentamos os resultados e na parte cinco o trabalho é concluído.

\section{REFERENCIAL TEÓRICO}

Neste capítulo nós apresentamos uma revisão da literatura da Teoria Baseada em Recursos e dos dois principais construtos desta pesquisa: o fracasso em projetos e o sucesso em projetos, bem como das metodologias de gerenciamento de projetos considerando a corrente crítica e o $P M B O K ®$.

\subsection{Teoria Baseada em Recursos (TBR)}

A Teoria Baseada em Recursos (TBR) corresponde à teoria de sustentação para este trabalho, pois fornece a fundamentação e estrutura teórica tanto para capacidades organizacionais quanto competências estratégicas. Do ponto de vista de gerenciamento de projetos, ainda há uma carência de estudos sob a ótica da TBR (JUGDEV, 2004), porém, considerando que o construto é discutido como uma importante capability (CRAWFORD, 2006; CRAWFORD; HOBBS; TURNER, 2006; KERZNER, 2011) deve estar alinhado com os aspectos estratégicos da empresa (DINSMORE; COOKE-DAVIES, 2006; PMI, 2008). Nesse caso, a TBR fornece a ancora teórica que suporta o estudo das rotinas e competências organizacionais na gestão de projetos, uma vez que também incorpora estas capacidades (PEDROSA; CARVALHO, 2014).

Essa teoria tem sido largamente estudada no contexto da literatura de estratégia e operações estratégicas, principalmente, em função da mesma permitir o entendimento de como as empresas 
podem competir e manter uma posição defensável no mercado em que atuam, mediante seus recursos internos que devem ser valiosos, raro, difícil de imitar e difícil de substituir (BARNEY, 1991; DINSMORE; COOKE-DAVIES, 2006; JUGDEV; MATHUR; FUNG, 2007; PETERAF, 1993; RAY; BARNEY; MUHANNA, 2004; TEECE; PISANO; SHUEN, 1997; WERNERFELT, 1984). Posteriormente, Barney e Wright (1998) reviram o conceito "difícil de substituir" propondo uma alteração para "organizacional", o qual relacionam aos recursos estratégicos e redefinem a estrutura para VRIO. Sob essa estrutura, os ativos estratégicos (tangíveis ou intangíveis) constituem as fontes de vantagem competitiva de uma empresa (BARNEY, 1991; JUGDEV; MATHUR; FUNG, 2007; PETERAF, 1993; TEECE; PISANO; SHUEN, 1997; WERNERFELT, 1984). Abaixo, apresentamos a definição da estrutura VRIO baseado nessa literatura:

- Valioso: é definido por sua característica econômica ou financeira do recurso na geração de caixa;

- Raros: caracteriza-se por ser único. Poucas empresas têm acesso a esse recurso estratégico;

- Inimitável: corresponde à característica do recurso que ainda representa barreiras à imitação ou replicação por parte dos competidores; e

- Organizacional: está relacionado ao apoio gerencial, bem como aos processos e sistemas que suportam os recursos estratégicos.

Os recursos são a essência dessa teoria, segundo Eisenhardt e Martin (2000). São através desses que a empresa compete no mercado mediante a geração de um pacote de valor que o segmento-alvo aprecia. Para a TBR, os recursos e competências são definidos como ativos, capacidades, processos e conhecimentos inerentes à empresa. Penrose (1959) e Barney (1991) consideram tanto os ativos tangíveis quanto intangíveis quando fazem referência aos quesitos ativos e competências. Ou seja, a combinação de recursos e competências estratégicas é que pode fazer a diferença no ambiente em que a empresa atua. Em gestão de projetos, a evolução constante das competências internas da organização no gerenciamento pode constituir uma fonte chave de sucesso e de melhoria no desempenho destes projetos (SCHELINI; MARTENS; PISCOPO, 2017) 
Schoenherr et al. (2012) sugerem que uma competência competitiva importante pode afetar o resultado à medida que esta habilidade representa um recurso valioso tanto interno (provê melhoramento) quanto externo (provê vantagem competitiva). Contrastando com essa perspectiva, Peng, Schroeder e Shah (2008) sugerem que os recursos são um conjunto de rotinas e práticas organizacionais que visam alcançar um determinado resultado ou metas. Ainda em linha com essa visão, Coates e McDermott (2002) complementam que a maneira como a empresa utiliza seus recursos e capabilities é que permite capturar o dinamismo do comportamento concorrencial, ou seja, destacam o relacionamento com o mercado. Já Ghemawat e Rivkin (2006) preferem discutir o aspecto da sustentação da vantagem competitiva mediante a integração do conjunto de decisões que proporcionam uma distinção da empresa frente a seus principais concorrentes.

A adoção da TBR como fundamentação teórica para este trabalho está baseada nas seguintes considerações a seguir: (i) a justificativa da importância do aspecto estratégico de gerenciamento de projetos como capability organizacional (CRAWFORD; HOBBS; TURNER, 2006; JUGDEV, 2004; JUGDEV; MATHUR; FUNG, 2007); (ii) considerando que o gerenciamento de projetos pode ser um recurso essencial à empresa deve, portanto, fazer parte da estrutura VRIO (JUGDEV; MATHUR; FUNG, 2007); (iii) a TBR ainda é pouco estudada na literatura de projetos, principalmente, porque esta disciplina ainda é bastante recente (JUGDEV, 2004); e (iv) a área de gestão de projetos também carece de uma teoria de suporte (ENGWALL, 2003; JUGDEV, 2004). Considerando essa última justificativa, os vários guias de conhecimentos em gerenciamento de projetos focam nas dimensões técnicas do gerenciamento (custo, prazos, qualidade e escopo), nas qualificações e competências profissionais, mas não abordam as teorias de suporte em gerenciamento de projetos (JUGDEV, 2004).

Wacker (1998) aponta que uma boa teoria deveria fornecer uma estrutura analítica a qual diferentes pontos de vistas são considerados. Já Van de Ven (1989) argumenta que uma teoria deve ser capaz de não somente justificar empiricamente os padrões, mas explicar suas causas. Em consonância com essa visão, Jugdev (2004) destaca que as teorias são fundamentais, pois ajudam a explicar e prever 
eventos, padrões e tendências. Porém, Stratton (2009) argumenta que embora tenhamos presenciado avanços no conhecimento em gestão, há muito que se fazer pelo desenvolvimento da uma teoria na área de gerenciamento de projetos.

\subsection{Fracasso em projetos}

A literatura é farta em relatar casos de fracassos em gerenciamento de projetos, principalmente, na área de tecnologia da informação (TI) (ALAMI, 2016; HUSSAIN; MKPOJIOGU, 2016; KEIL; MÄHRING, 2010; ROBERTSON; WILLIAMS, 2006). Segundo Aubry e Lièvre (2010), apesar dos esforços tanto de profissionais quanto de acadêmicos, ainda há muito descontentamento considerando às questões teóricas e práticas relacionadas à gestão de projetos. Um fator importante desse sentimento decorre da taxa de sucesso de projetos que é muita baixa tanto em projetos públicos quanto em projetos de grandes corporações. Levasseur (2010) sugere que os principais fatores que contribuem ao fracasso em projetos são os métodos utilizados pelos gestores no processo de gestão de mudança. Destaca-se que 65\% da taxa de fracasso em projetos são devidas à gestão da mudança que não é bem implementada e que os 35\% restantes estão relacionados a problemas técnicos (LEVASSEUR, 2010; MCMANUS; WOOD-HARPER, 2007). Levantamento feito por instituto de pesquisa americano independente constatou que $24,0 \%$ dos projetos em termos mundiais foram cancelados antes de serem completados, 63,0\% não terminaram no prazo e 45,0\% ultrapassaram os orçamentos iniciais (THE STANDISH GROUP, 2001, 2009). Dentre os problemas apontados por esse instituto, estão relacionados ao trabalho colaborativo insuficiente e os problemas técnicos dentre os quais abordam o não cumprimento do escopo inicial, orçamentos e prazos que geram impactos negativos em projetos. Para Mahaney e Lederer (2011), uma possível explicação para essa taxa elevada de fracassos em projetos pode ser atribuída a fatores comportamentais relacionados à equipe, bem como a fatores inerentes à gestão de projetos. Os problemas gerados em função de uma iniciativa malfadada aparecem, principalmente, na violenta elevação de custos das organizações, o que geram desperdícios tanto de recursos quanto de oportunidades (KEIL; MÄHRING, 2010; MAHANEY; LEDERER, 2011). 
Shepherd et al. (2011) consideram que o fracasso em projetos tem como característica o encerramento de uma iniciativa visando à geração de valor à organização, na qual ficou aquém das expectativas. Porém, o encerramento de tal empreendimento gera emoções negativas nos membros da organização e estas emoções estão associadas ao baixo nível de comprometimento individual para com a organização. Shepherd et al. (2011) ainda sugerem que as lições aprendidas decorrentes do fracasso não são instantâneas e nem automáticas, pois dependem de como a organização se posiciona em relação ao evento ocorrido. Já Hussain e Mkpojiogu (2016) apontam que a engenharia de requisitos, que é um processo de produção de um documento dos requisitos, é a base de todo o projeto de software. Os processos de requisitos mal projetados contribuem para falhas em projetos de software. Portanto, projetos de desenvolvimento de softwares podem ser prejudicados ou sofrerão falhas, ou mesmo outros riscos associados se não atentarem adequadamente para essa questão. Para Alami (2016), como o desenvolvimento de projetos em TI exclusivos estão se tornando cada vez mais ambiciosos em termos de quantidade, objetivos e escala, portanto, as falhas podem ocorrer considerando esse amplo volume de projetos especiais existentes.

Blackstone Jr, Cox III e Schleier Jr (2009), Levasseur (2010) e Keil e Mähring (2010) também argumentam que outros fatores pertinentes à gestão, que corroboram com o declínio de projetos, estão relacionados ao não envolvimento dos stakeholders nas fases iniciais de definição do escopo. Isso corresponde a um dos fatores preponderantes ao fracasso, porém, também é importante o entendimento de outros fatores que afetam estes processos como, por exemplo, a falta de apoio da alta administração, a incapacidade de obter o comprometimento dos usuários, o baixo comprometimento dos membros da equipe de projetos, e a discordância dos stakeholders quanto ao direcionamento do projeto. Mudanças que afetam o escopo também geram impactos negativos em custos (NOKES; KELLY, 2012) levando ao não cumprimento dos aspectos técnicos. Blackstone Jr, Cox III, e Schleier Jr (2009) enfatizam que normalmente os atrasos na gestão tradicional de projetos são decorrentes da falta de liderança, baixo envolvimento do usuário, falta de competências e habilidades necessárias à execução, falta de comunicação entre as partes interessadas e de gestão, falta de apoio 
da alta gerência, definição de requisitos insuficientes (os prazos e a infraestrutura são estimados incorretamente), dentre outros. Nokes e Kelly (2012) argumentam que os aspectos culturais (e os fatores organizacionais gerados por eles) quase sempre estão por trás dos problemas de desempenho cotidianos enfrentados pelos gerentes de projetos. Por outro lado, Savage, Hilton e Thibault (2011) apontam que os problemas em gerenciamento de projetos têm sua origem no que se denomina o problema das médias. Segundo eles, esses problemas ocorrem devido às estimativas serem baseadas em médias (custos médios, prazos médios, multas médias, etc.), o que acarreta erros de estimativas quando comparados à realidade. Fern e Zarei-Kesheh (2011) também argumentam que cada projeto é cheio de incertezas, ou seja, coisas que ignoramos e que impactarão o custo e o prazo do projeto e, ocasionalmente, à capacidade em terminá-lo. Para lidar com incertezas, estes autores propõem o conceito de Tratado de Medidas Confiáveis de Conclusão (TMCC) que representa um método para medir o progresso com ênfase na identificação e estimativa das consequências das possíveis incertezas tanto em termos de tempo quanto financeiro. Segundo os autores, essa resolução precoce economiza tempo e esforços gastos em projetos que não podem ser concluídos. Ainda considerando incertezas em projetos, Mikaelian, Nightingale, Rhodes e Hastings (2011) propõem introduzir a flexibilidade no processo, a qual pode ser modelada e valorizada mediante uma Análise de Opções Reais (ROA). Com base nessa alternativa, a introdução da flexibilidade melhora a capacidade da organização em expandir um projeto em decorrência da demanda crescente, mediante o deslocamento de seus recursos. Geraldi, Lee-Kelley e Kutsch (2010) também avaliam que eventos inesperados podem impactar negativamente em projetos e propõem três pilares visando responder adequadamente a este risco, são eles: estrutura responsiva e de funcionamento, bom relacionamento interpessoal e pessoas competentes.

Cui, Zhao e Ravichandran (2011) avaliando as estratégias de lançamento de novos produtos, propõem um modelo de sistema dinâmico no qual permite ajustar as estratégias de lançamento de novos produtos às incertezas de mercado. A adoção dessa flexibilidade estratégica torna-se fundamental nesses processos, pois o planejamento estratégico em pré-lançamento é crítico para o sucesso 
do lançamento, principalmente, para produtos realmente novos e diante de incertezas.

Love, Davis, Cheung e Irani (2011) analisando o mercado australiano da construção civil, argumentam que problemas ambientais e comportamentais levam ao aparecimento de disputas em projetos. As causas para essas disputas ocorrem em função, por exemplo, da alocação de risco injusta, definição de metas irrealistas pelo cliente considerando tempo, custo, qualidade, expectativas irrealistas de informação, documentação inadequada, formas de contratos inapropriados, comunicação pobre, retrabalhos, aprovação tardia por parte do gestor, dentre outras. Enquanto problemas, como os citados acima, não forem atacados mediante uma gestão eficaz de projetos, essas deficiências continuarão e de certa forma impactarão no dimensionamento dos recursos (financeiros, materiais e humanos). Outro aspecto observado por Shahhossein, Afshar e Amiri (2017) é que projetos no setor de construção civil indicam fracassos pela não realização de seus orçamentos.

Portanto, o não cumprimento do orçamento, conforme planejado, perde sua justificativa econômica e assim os projetos fracassam. Já Moura, Carneiro e Freitas (2018) destacam que variáveis como planejamento do projeto, complexidade do projeto, o envolvimento da equipe e o comprometimento dos usuários são variáveis que impactam o sucesso dos projetos de software.

Embora haja boas metodologias vigentes (PMBOK®; Corrente Crítica, dentre outras), Aubry e Lièvre (2010) destacam que o fracasso também pode ser explicado pela falta de rigor na aplicação das práticas e procedimentos sugeridos por estas metodologias. Também para Levasseur (2010), a aplicação efetiva de métodos de gestão de mudança melhora potencialmente a taxa de sucesso em projetos. Ainda com relação à metodologia de projetos, Raz, Barnes e Dvir (2003) afirmam que para a adoção da prática na gestão de projetos, deve-se investir maciçamente em educação considerando os vários níveis e funções organizacionais visando absorver a metodologia a ser utilizada. Baker (2002) afirma que uma falha na estratégia do projeto pode gerar grandes problemas futuros, principalmente, quando estes afetam as vidas das pessoas. 


\title{
A Tabela 1 abaixo apresenta os principais fatores que levam ao fracasso de projetos.
}

\author{
Tabela 1 - Fatores que levam ao fracasso de projetos
}

\begin{tabular}{|c|c|}
\hline Fatores & Referências \\
\hline Processo de gestão de mudança. & Levasseur (2010) \\
\hline $\begin{array}{l}\text { Trabalho colaborativo insuficiente, problemas técni- } \\
\text { cos, não cumprimento do escopo inicial, orçamentos e } \\
\text { prazos. }\end{array}$ & $\begin{array}{l}\text { The Standish Group (2001, } \\
\text { 2009) }\end{array}$ \\
\hline $\begin{array}{l}\text { Fatores comportamentais relacionados à equipe, fatores } \\
\text { inerentes à gestão de projetos. }\end{array}$ & Mahaney e Lederer (2011) \\
\hline Elevação dos Custos. & $\begin{array}{l}\text { Keil e Mähring (2010), } \\
\text { Mahaney e Lederer (2011) }\end{array}$ \\
\hline $\begin{array}{l}\text { Encerramento de iniciativas visando gerar valor à } \\
\text { organização. }\end{array}$ & $\begin{array}{l}\text { Shepherd, Patzelt e Wolfe } \\
\text { (2011) }\end{array}$ \\
\hline $\begin{array}{l}\text { Levantamento e engenharia de requisitos de software } \\
\text { insuficientes. }\end{array}$ & Hussain e Mkpojiogu (2016) \\
\hline Elevada quantidade de projetos, objetivos e escala. & Alami (2016) \\
\hline $\begin{array}{l}\text { Não envolvimento dos stakeholders na definição do } \\
\text { escopo, falta de apoio da alta administração, falta de } \\
\text { comprometimento dos usuários, baixo comprometimen- } \\
\text { to dos membros da equipe, discordância dos stakehol- } \\
\text { ders quanto ao direcionamento do projeto, e alterações } \\
\text { do escopo. }\end{array}$ & $\begin{array}{l}\text { Blackstone Jr, Cox III e } \\
\text { Schleier Jr (2009), Levasseur } \\
\text { (2010), Mahaney e Lederer } \\
\text { (2011) }\end{array}$ \\
\hline $\begin{array}{l}\text { Atrasos pela falta de liderança, baixo envolvimento } \\
\text { do usuário, falta de competências e habilidades em } \\
\text { projetos, falta de comunicação com stakeholders, falta de } \\
\text { apoio da alta gerência, requisitos insuficientes. }\end{array}$ & $\begin{array}{l}\text { Blackstone Jr, Cox III e } \\
\text { Schleier Jr (2009) }\end{array}$ \\
\hline Aspectos culturais. & Nokes e Kelly (2012) \\
\hline $\begin{array}{l}\text { Estimativas (custos) serem baseadas em médias (custos } \\
\text { médios, prazos médios, multas médias, etc.). }\end{array}$ & $\begin{array}{l}\text { Savage, Hilton e Thibault } \\
\text { (2011) }\end{array}$ \\
\hline Incertezas e eventos inesperados. & $\begin{array}{l}\text { Fern e Zarei-Kesheh (2011), } \\
\text { Geraldi, Lee-Kelley e Kutsch } \\
\text { (2010) }\end{array}$ \\
\hline Problemas ambientais e comportamentais. & Love et al. (2011) \\
\hline Não cumprir o projeto dentro do orçamento planejado. & $\begin{array}{l}\text { Shahhossein, Afshar e Amiri } \\
\text { (2017) }\end{array}$ \\
\hline $\begin{array}{l}\text { Planejamento do projeto, complexidade do projeto, } \\
\text { envolvimento da equipe e comprometimento dos usu- } \\
\text { ários. }\end{array}$ & $\begin{array}{l}\text { Moura, Carneiro e Freitas } \\
(2018)\end{array}$ \\
\hline Falta de rigor na aplicação das metodologias de projetos. & Aubry e Lièvre (2010) \\
\hline Falha estratégica do projeto. & Baker (2002) \\
\hline
\end{tabular}

Fonte: Elaborado pelos autores 


\subsection{Sucesso em projetos}

O entendimento dos fatores que impactam em fracasso do projeto é fundamental, pois uma vez identificadas, pode-se minimizar as influências sobre os projetos e por consequência elevar a taxa de sucesso. Nesse sentido, tanto profissionais quanto acadêmicos estão buscando novas técnicas, novas propostas para um gerenciamento adequado de projeto (KENDRA; TAPLIN, 2004), ou seja, que cumpra os requisitos atribuídos a ele (MAHANEY; LEDERER, 2011) quer do ponto de vista técnico, quer do ponto de vista dos benefícios gerados (PINTO; SLEVIN, 1988).

A partir de 2001, as empresa de manufatura começaram a avaliar novos métodos de gestão de projetos visando melhorar o desempenho (KENDRA; TAPLIN, 2004). Essas iniciativas focaram no crescimento das capabilities em gestão de projetos que estão alicerçadas no aumento das competências do gerente do projeto, na concepção de novas métricas para avaliar o desempenho individual, processo de negócio, estrutura da organização por projeto e práticas gerenciais (KENDRA; TAPLIN, 2004). Quanto às competências dos gerentes de projeto, Henderson (2008) analisa que quando os gestores codificam ou decodificam de forma eficiente a comunicação, melhoram significativamente a satisfação e produtividade dos membros da equipe de projetos. Para Mazur et al. (2014), a comunicação efetiva e de qualidade com os stakeholders pode contribuir para o sucesso do projeto. Por outro lado, Hyejung, Park e Jungwoo (2013), Zhang e Fan (2013), Trejo (2014) destacam que o elemento da inteligência emocional independentemente do tempo de projeto, influência diretamente no desempenho do projeto.

Do ponto de vista da questão estratégica, Dinsmore e Cooke-Davies (2006) e Piyush, Dangayach e Mittal (2011) sugerem que as organizações utilizam os projetos para implementar suas estratégias visando alcançar seus objetivos organizacionais e para isto necessitam de gerentes de projetos competentes. Marques Junior e Plonski (2011) referendam essa visão sugerindo que os projetos são os vetores das mudanças, da implementação das estratégias e de inovações que trazem vantagens competitivas às empresas.

Considerando as características de um gerente eficaz, Piyush, Dangayach e Mittal (2011) argumentam que estas estão baseadas no 
comportamento de liderança que corresponde aos fatores humanos fundamentais ao sucesso de projetos. Por exemplo, Marzagão e Carvalho (2016) destacam que o comportamento inovador do líder, a sua capacidade de adaptação e da adoção de soluções criativas, ou mesmo um líder com mente aberta podem ser fatores que levam à melhoria do desempenho de projetos. Shao, Müller e Turner (2012) exploram que do ponto de vista de sucesso em programas vale a identificação dos benefícios gerados por este que podem ser classificados em financeiros e não financeiros, tangíveis e intangíveis. Os resultados apontados por Shao, Müller e Turner (2012) indicam que o construto de sucesso em programas estão concentrados em quatro dimensões básicas: capacidade de entrega, capacidade organizacional, capacidade de marketing e capacidade de inovação. A capacidade de entrega está relacionada aos benefícios tangíveis; já as outras, aos benefícios intangíveis. Talvez um questionamento possível aqui seria considerar que se um projeto atendesse a determinadas características tanto do ponto de vista técnico quanto de benefícios auferidos, ele seria considerado um sucesso? Nesse caso ainda não há um consenso na literatura quanto à definição do que é sucesso ou fracasso em projeto dado que ela ainda está em sua infância (IKA, 2009; PINTO; SLEVIN, 1988; SHAO, MÜLLER; TURNER, 2012). Segundo Ika (2009), há um campo fértil de pesquisa visando à definição desses construtos e, portanto, representa enormes desafios aos pesquisadores. Ika (2009) ainda aponta que há uma ambiguidade na definição de sucesso em projeto, pois além do conceito ser multidimensional, é aplicado em um ambiente específico no qual o sucesso em projeto pode ter uma relação tanto do ponto de vista de gerenciamento quanto dos resultados auferidos. Quanto ao gerenciamento, o sucesso reside na concepção de que as dimensões mais comuns como: custo, prazos e qualidade devem ser atingidas (IKA, 2009; MAHANEY; LEDERER, 2011; SHAO; MÜLLER; TURNER, 2012). No entanto, isso não garante que o produto ou serviço decorrente do projeto seja um sucesso de vendas e atinja os resultados esperados. Há situações nas quais essas dimensões não foram atingidas, mas os resultados provenientes ficaram acima das expectativas (DE WIT, 1988; PINTO; SLEVIN, 1988). De Wit (1988) ainda entende que avaliar o sucesso em projetos baseado apenas 
em critérios técnicos é irrelevante. Para ele, o projeto pode ser considerado um sucesso caso atenda um certo nível de satisfação das pessoas chaves na organização: equipe de projetos, usuários e clientes (BACCARINI, 1999; BAKER, MURPHY; FISHER, 2008; DE WIT, 1988). Baccarini (1999) ainda considera que o construto "sucesso em projeto" deva ser analisado sob duas perspectivas: sucesso no gerenciamento de projeto e sucesso do produto. A primeira se refere à avaliação do processo onde os custos, prazos e qualidade devam ser atendidos; a segunda, decorre dos resultados e/ou benefícios gerados. Lim e Mohamed (1999) citam exemplos de projetos nessa categoria (o Concorde, a Sydney Opera House e a primeira geração do carro Ford Taurus) que tiveram desempenho técnico insatisfatório, mas que os resultados gerados foram importantes. Martin, Pearson e Furumo (2007) complementam que os projetos deveriam ser taxados como sucesso caso completassem ou estivessem próximo às estimativas planejadas, ou seja, cumprissem o orçamento e ainda tivessem níveis aceitáveis de desempenho. Adicionalmente, Cruz, Scur e Carvalho (2018) atribuem as dimensões, equipe, cliente, negócio, produto e sustentabilidade como relevantes ao sucesso do projeto. Já Mukerjee e Prasad (2017) complementam essa ideia ao afirmarem que a seleção de uma solução de um fornecedor, bem como seu papel na solução e seu engajamento inicial são fatores que contribuem para alavancar o desempenho do projeto.

Entretanto, Lim e Mohamed (1999) entendem que o sucesso em projeto deva ser visto sob diferentes perspectivas, pois as expectativas das partes interessadas (gerente do projeto; stakeholders, público em geral) divergem. O que é bom para um; deixa a desejar para outro (LIM; MOHAMED, 1999).

A analogia que se faz considerando esses dois aspectos de avaliação do construto é com relação ao conceito de eficiência e eficácia no qual o sucesso de projeto pode ser contextualizado sob a ótica do gerenciamento em termos de respeito às dimensões mais técnicas como custos, prazos, qualidade e o escopo (AUBRY; LIÈVRE, 2010; IKA, 2009; MAHANEY; LEDERER, 2011). Nesse caso, o conceito de eficiência seria mais apropriado, pois os recursos deveriam ser utilizados de forma adequada e sem desperdício. Já os resultados auferidos pelo projeto poderiam ser suportados pelo conceito de 
eficácia à medida que os objetivos organizacionais são atingidos (BELOUT, 1998). No entanto, segundo Ika (2009), não há consenso na literatura quanto aos conceitos de eficiência e eficácia atrelados aos construtos em análise. Para Shao, Müller e Turner (2012) esses construtos deveriam ser avaliados sob o contexto de fatores ou critérios que levam em conta o desempenho. Já Mahaney e Lederer (2011) analisando uma possível explicação para o sucesso ou fracasso em projetos com base na teoria da agência, destacam que o monitoramento do projeto por parte do agente possibilitaria a elevação da taxa de sucesso à medida que a identificação dos problemas ocorreria já nos estágios iniciais de sua implementação. Isso permitiria possíveis correções pelo gerente do projeto minimizando o agravamento do problema.

Ding e Ding (2008) discutem formas de melhorar o gerenciamento de projetos tendo como foco a equipe e a comunicação. Segundo eles, o processo decisório colaborativo através da negociação democrática é um componente-chave na abordagem orientada ao processo de trabalho em equipe e deve começar logo no início das atividades quando todos os membros da equipe trabalham em conjunto para definir os objetivos, escopo, pessoal e logística. Lenfle e Loch (2010) argumentam que o projeto é o veículo para a organização de aprendizagem e que o desafio deste está no que separa o que é desejado do que é viável, mas também é uma fonte essencial de insight sobre os desafios estratégicos da organização e suas soluções.

A Tabela 2 a seguir apresenta os principais fatores que levam ao sucesso de projetos.

Metodologias de Gerenciamento de Projetos: Corrente Crítica e Guia PMBOK®

Existem várias alternativas que ao longo dos anos se apresentaram visando melhorar a gestão de projetos. O Project Management Body of Knowledge (PMBOK®) (PMI, 2008) foi uma alternativa desenvolvida por acadêmicos e profissionais de gestão para suprir essa necessidade de gerenciamento. O $P M B O K ®$ consiste, na verdade, em um conjunto de boas práticas em gerência de projetos e é largamente aceito, mas, segundo Bouer e Carvalho (2005), não deve ser aplicado de forma uniforme a todos os tipos de empresa. 
Tabela 2 - Fatores que levam ao sucesso de projetos

\begin{tabular}{|c|c|}
\hline Fatores & Referências \\
\hline $\begin{array}{l}\text { Práticas de gestão de projetos, treinamento maciço na } \\
\text { metodologia de projetos. }\end{array}$ & Raz, Barnes e Dvir (2003) \\
\hline Competências do gerente de projeto, comunicação eficiente. & Henderson (2008) \\
\hline Comunicação com os stakeholders. & Mazur et al. (2014) \\
\hline $\begin{array}{l}\text { Inteligência emocional influência diretamente o desempe- } \\
\text { nho do projeto }\end{array}$ & $\begin{array}{l}\text { Hyejung, Park e Jungwoo } \\
\text { (2013), Trejo (2014), } \\
\text { Zhang e Fan (2013) }\end{array}$ \\
\hline $\begin{array}{l}\text { Competências dos gerentes de projeto para implantar as } \\
\text { estratégias e alcançar os objetivos organizacionais. }\end{array}$ & $\begin{array}{l}\text { Dinsmore e Cooke-Davies } \\
\text { (2006), Piyush, Dangayach } \\
\text { e Mittal (2011) }\end{array}$ \\
\hline Liderança do gerente do projeto. & $\begin{array}{l}\text { Piyush, Dangayach e } \\
\text { Mittal (2011) }\end{array}$ \\
\hline $\begin{array}{l}\text { Comportamento inovador do líder, capacidade de adapta- } \\
\text { ção e adoção de soluções criativas, líder com mente aberta. }\end{array}$ & $\begin{array}{l}\text { Marzagão e Carvalho } \\
(2016)\end{array}$ \\
\hline $\begin{array}{l}\text { Capacidade de entrega, capacidade organizacional, capaci- } \\
\text { dade de marketing, e capacidade de inovação. }\end{array}$ & $\begin{array}{l}\text { Shao, Müller e Turner } \\
(2012)\end{array}$ \\
\hline Atingimento de custo, prazos e qualidade. & $\begin{array}{l}\text { Ika (2009), Mahaney e Le- } \\
\text { derer (2006), Shao, Müller } \\
\text { e Turner (2012) }\end{array}$ \\
\hline Satisfação de pessoas chaves na organização & De Wit (1988) \\
\hline Satisfação do Cliente. & $\begin{array}{l}\text { Baccarini (1999), } \\
\text { Baker, Murphy, Fisher } \\
\text { (2008), De Wit (1988) }\end{array}$ \\
\hline Sucesso no gerenciamento de projeto e sucesso do produto. & Baccarini (1999) \\
\hline Equipe, cliente, negócio, produto e sustentabilidade. & $\begin{array}{l}\text { Cruz, Scur e Carvalho } \\
\text { (2018) }\end{array}$ \\
\hline $\begin{array}{l}\text { Análise de diferentes perspectivas: gerente do projeto, } \\
\text { stakeholders, público em geral. }\end{array}$ & Lim e Mohamed (1999) \\
\hline Fornecedores: seleção, papel e engajamento. & Mukerjee e Prasad (2017) \\
\hline Monitoramento do projeto. & Mahaney e Lederer (2011) \\
\hline
\end{tabular}

Fonte: Elaborado pelos autores

Outra alternativa em gestão de projetos é a metodologia desenvolvida por Eliyahu Goldratt batizada de Corrente Crítica (GOLDRATT, 1997) que consiste numa metodologia de gestão de projeto embasada na filosofia da Teoria da Restrição (TOC). Em 1997, preocupado com os problemas oriundos da gestão de projetos e fundamentado nos conceitos do Thinking Process (KIM, MABIN; DAVIES, 2008) e da TOC (GOLDRATT; COX, 1990; GOLDRATT; FOX, 1986) aplicada à produção seriada, desenvolveu uma nova filosofia para a gestão enxuta e redu- 
ção de prazo de entrega de projetos denominada de Corrente Crítica. Considerando que essa metodologia está embasada nos fundamentos da TOC, Rahman $(1998,2002)$ argumenta que diante da existência de restrições, há oportunidades para a melhoria e que estas restrições sob ótica da TOC não são vistas nem como positivas e nem como negativas. As restrições determinam o desempenho, pois à medida que se eleva o gargalo do sistema, o desempenho também é elevado (RAHMAN, 1998, 2002). Em projetos isso significa proteger a Corrente Crítica.

Segundo Stratton (2009), a adoção da CCPM se popularizou a partir dos problemas apontados na literatura na gestão de projetos, bem como pela falta de uma teoria que suportasse este gerenciamento. Casos de sucesso são relatados pelo autor usando essa metodologia, por exemplo: Sunagogumi, Hewlett Packard, e ABB. Mourão (2007) também discorre sobre os projetos implantados pela empresa Vale que também foram casos de sucesso utilizando a CCPM. Com base nessa metodologia, as pesquisas demonstraram que em $95 \%$ dos projetos que aplicaram a CCPM de forma correta conseguiram respeitar prazos e orçamentos definidos inicialmente (BALDERSTONE; MABIN, 1998; MABIN; BALDERSTONE, 2003). Leach (1999) também afirma que o gerenciamento de projetos baseado na CCPM proporciona um avanço substancial em melhoramento contínuo em relação ao $P M B O K ®$. Segundo ele, isso deriva da aplicação da Teoria das Restrições e das Teorias Estatísticas ao sistema de projeto.

O conceito de "caminho crítico" estabelecido pelo PMBOK® entende como uma sequência de atividades planejadas ao longo do projeto, que contabilizam a menor folga de tempo. Consequentemente, o gestor de projeto deve dar a devida atenção a essa sequência. Diferentemente do caminho crítico, Goldratt considerou a corrente crítica dependente da existência de recursos disponíveis. Embora a Corrente Crítica seja similar ao Caminho Crítico, três grandes diferenças são enfatizadas por esta metodologia: o método de avaliação do tempo das atividades, a utilização dos buffers (pulmões) e a eliminação de conflitos entre recursos (WATSON; BLACKSTONE; GARDINER, 2007). Esse método se baseia em: reduzir agressivamente o tempo de duração das tarefas, já que as estimativas de segurança muitas vezes escondem as folgas, a margem de segurança de execução do projeto é dimensionada de forma holística e não visa às tarefas individuais, todos os integrantes 
do projeto têm uma visão global de eventos que atrasam o projeto e são evidenciados, iniciar realmente a tarefa do projeto quando está realmente na hora de iniciar e não antes, fomentar o engajamento das pessoas em realizar as tarefas o mais rápido possível uma vez designado, eliminar o conflito de recursos por meio do método do Thinking Process (TOC-TP), controlar frequentemente o pulmão do projeto, e levar em consideração os fundamentos da flutuação estatística.

O conjunto de princípios definidos por Goldratt para a CCPM é essencialmente normativo e pragmático. No entanto, o que determina o sucesso dessa metodologia pode ser atribuído a uma mudança comportamental, o que justificaria a adoção da CCPM.

Os estudos existentes têm apontado para a necessidade de mudança comportamental visando à aceitação de novos valores e paradigmas (BENDOLY; HUR, 2007; HERROELEN; LEUS, 2001). Diante disso, Bendoly e Hur (2007) argumentam que uma parte do sucesso dos projetos gerenciados por meio da corrente crítica pode ser atribuída à compatibilidade das crenças, valores das pessoas e da organização com os valores apontados por este novo método. Por exemplo, "fazer o trabalho sempre no menor tempo necessário", "não deixar para depois o que pode fazer agora", "o que importa é o resultado global e não o resultado local", "não deixar que sua mente se torne uma restrição no sistema", "melhorar e procurar sempre pela próxima restrição", "a fraqueza da corrente localiza-se no seu elo mais fraco", dentre outros. Esses são comportamentos, que de certa forma, levam a uma condição da busca pela excelência.

Bendoly, Donohue e Schultz (2006) argumentam que a área de Gestão de Operações carece de pesquisas, bem como de teorias que discutam a gestão da mudança. Diante dessa constatação, a metodologia da Corrente Crítica se apresenta como uma alternativa. Para Froehle e Roth (2004) as teorias que suportam a gestão da mudança são oriundas das ciências sociais ou da psicologia, tais como Teoria do Comportamento Planejado ou Teoria da Ação Racional. Essas teorias argumentam que o comportamento do indivíduo é decorrente da sua intenção e esta é influenciada pelas atitudes que por sua vez é resultante das crenças subjetivas (Fishbein e Ajzen, 1975). Segundo Fishbein e Ajzen (1975), a atitude se refere a uma avalição favorável ou não favorável em relação ao objeto, enquanto que a crença se refere à informação que uma pessoa 
tem acerca do objeto. As crenças são entendidas como subjacentes às atitudes e às normas subjetivas, o que, em última instância, as coloca como determinantes das intenções e comportamentos (MOUTINHO; ROAZZI, 2010). Ainda com relação à atitude, Ajzen e Fishbein (1980) afirmam que quanto mais favorável estiver em relação ao objeto, maior será sua intenção em relação a ele. O termo objeto, nesse caso, está colocado num sentido genérico podendo se referir a qualquer aspecto do mundo do indivíduo (FISHBEIN; AJZEN, 1975). Moutinho e Roazzi (2010) consideram que o objeto pode ser relacionado às pessoas, grupos, instituições e comportamentos.

Quanto ao comportamento intencional, este se refere às intenções das pessoas em desempenhar vários comportamentos (atos observáveis). Para Fishbein e Ajzen (1975), a intenção pode ser vista como um caso especial de crenças, no qual o objeto estaria relacionado à pessoa em si e o atributo estaria relacionado ao comportamento. Moutinho e Roazzi (2010) também apontam que as intenções são assumidas como disposições para realização do comportamento. Ajzen e Fishbein (1980) argumentam que as intenções também são influenciadas pelas normas subjetivas e que estas dizem respeito à percepção da pessoa sobre a pressão socialmente exercida sobre o sujeito no sentido de incentivar ou não a execução do comportamento, ou seja, referem-se à percepção da pessoa quanto à pressão social exercida sobre ela para que realize ou não um comportamento (MOUTINHO; ROAZZI, 2010). Essas normas subjetivas são determinadas pelas crenças normativas que também são reguladoras do comportamento. Para Huesmann e Guerra (1997), as crenças normativas correspondem à cognição individual de aceitabilidade ou não aceitabilidade a um comportamento. Assim, servem para regular esses comportamentos através da prescrição de uma variedade de ações correspondentes, que são permitidas ou proibidas. Em síntese, o comportamento é determinado pelas intenções, e estas são determinadas por atitudes e normas subjetivas e, por fim, as atitudes são determinadas por crenças e seus aspectos avaliativos (FISHBEIN; MIDDLESTADT, 1995). Em projetos, isso significa identificar quais questões organizacionais tais como: estruturas organizacionais, estruturas de poder, estilos de liderança, políticas, normas, métodos de trabalho que afetam ou regulam o comportamento dos indivíduos na organização tanto do ponto de vista positivo quanto negativo. Consi- 
derando que as pessoas, e somente as pessoas, executam os projetos, gerenciar projetos significa gerenciar pessoas (NOKES; KELLY, 2012). Bendoly, Donohue e Schultz (2006) ao revisar a literatura na área de Gestão de Operações, baseando-se nas dimensões da Teoria da Ação Racional, identificaram três categorias para a classificação destas publicações, a saber: Intenção, Ação e Reação. E notaram que o aspecto comportamental ainda é pouco explorado em Gestão de Operações.

\section{Metodologia}

O desenvolvimento dessa pesquisa é de caráter qualitativo exploratório e visa compreender quais fatores influenciam no desempenho de projetos. Para isso foram realizadas entrevistas semiestruturadas com participação de seis executivos (gerentes de projetos, coordenadores de projetos e consultores de projetos) de três empresas de setores distintos. Para Triviños (1987), a entrevista semiestruturada é um instrumento decisivo visando estudar os processos e produtos nos que o pesquisador qualitativo está interessado. Esse tipo de coleta de dados tem suas vantagens primeiramente por ter um questionário com perguntas específicas como também permite que o investigador explore outras questões que possam levar o entrevistado a expor suas opiniões, argumentos e pontos de vista (ALENCAR, 2000; COOPER; SCHINDLER, 2011; HAIR et al., 2005; VIEIRA, RIVERA 2012).

A amostra deste trabalho é composta por três empresas: $\mathrm{X}, \mathrm{Y}$ e $Z$. A empresa " $X$ " é uma multinacional de grande porte do setor de tecnologia da informação e com presença em mais de 170 países. O faturamento anual em torno de US\$79,9 bilhões (dados de 2016) e possui mais de 370.000 colaboradores em todo o mundo. Nessa empresa, foi entrevistado o gerente de risco de projetos, que conta com doze anos de experiência na área e é responsável por avaliar riscos em projetos usando a metodologia $P M B O K ®$ adaptada às necessidades da empresa. A entrevista foi presencial e durou aproximadamente duas horas.

A empresa " $Y$ " é uma multinacional de grande porte do setor de energia e automação, líder mundial no setor em que atua, e está presente em mais de 100 países. Apresentou um faturamento anual global acima de US\$33,4 Bilhões (2016) e possui mais de 135.000 
(2016) colaboradores em todo o mundo. No Brasil a empresa fatura em torno de $\mathrm{R} \$ 2,3$ bilhões (2016) e possui 3.000 colaboradores. A entrevista foi presencial e conduzida junto a profissionais da divisão de transformadores, na qual participaram três profissionais com mais de três de experiência na área de implementação de projetos usando como metodologia a CCPM. São eles: o gerente de projetos, o coordenador de planejamento para a área de serviços e a macroplanejadora da área de transformadores. A entrevista durou aproximadamente duas horas e meia.

A empresa "Z" é uma empresa nacional de grande porte do setor aeroespacial, com mais de 40 anos de existência e com faturamento anual acima de $\mathrm{R} \$ 21,0$ bilhões (2016). Possui fábricas no Brasil, França, EUA, Singapura, Portugal e China. Seus produtos são comercializados com 92 países. No Brasil, a empresa tem 18.000 colaboradores lotados em sua fábrica de São José dos Campos em São Paulo. O seu portfólio de produtos abrange projetos de desenvolvimento de produtos e suporte pós-venda (serviços) de aeronaves comerciais e executivas. A entrevista foi presencial e durou aproximadamente duas horas. Participaram dessa entrevista o gerente de planejamento integrado com mais de 20 anos de experiência na área e também um consultor interno de projetos em CCPM com mais de 27 anos de experiência.

A escolha dessas empresas se deu pelo porte e relevância em seus setores de atuação. Todas as entrevistas foram gravadas, à exceção da empresa " $Z$ ”, e analisadas mediante técnicas de análise de conteúdo (KRIPPENDORFF, 2012; MILES; HUBERMAN, 1994).

\section{DisCUSSÃo DOS RESULTADOS}

\section{Empresa $X$}

A empresa $X$ é considerada uma das maiores empresas do mundo na área de tecnologia da informação, desenvolve soluções locais e globais e possui um vasto portfólio de serviços e produtos tendo como pilares de negócio ofertas de serviços, consultoria, software e hardware. Adota a metodologia de boas práticas de gerenciamento de projetos a mais de uma década e meia, que é utilizada ampla- 
mente nas unidades de negócio de serviços de infraestrutura de TI no Brasil e no exterior. A partir de 2014, a empresa também passou a adotar métodos ágeis de gestão de projetos. As metodologias de projetos adotadas são adaptadas levando em consideração sua estrutura, cultura e características da indústria, tendo como referencial as melhores práticas de gestão de projetos como também os guias tradicionais de gerenciamento de projetos $P M B O K ®$. Sua operação funcional está baseada em uma estrutura matricial e parte de seus colaboradores já possuem a cultura de gerenciamento de projetos, além de serem certificados pela própria empresa e pelo PMI (Project Management Institute).

Um projeto pode se iniciar na fase de pré ou pós-venda. $\mathrm{Na}$ pré-venda, dependendo da complexidade do projeto, um ciclo para fechamento de uma proposta pode durar de 3 a 6 meses podendo, em alguns casos, ultrapassar a 1 ano. Ao fechar/assinar uma proposta, inicia-se a fase de implantação da solução vendida ao cliente, que pode ter como escopo a implantação de hardware, software e/ou serviços. Em ambos os casos um ou mais gerentes de projetos podem ser alocados para gerenciar todo o ciclo do projeto.

A empresa possui uma estrutura de Project Management Office (PMO) onde os projetos são controlados e uma estrutura de Quality Assurance, que atua de forma independente e que tem como objetivo identificar riscos dos projetos.

Para um experiente colaborador da empresa, gerente de projetos com mais de 10 anos na área, quando perguntado sobre o que ele entende por sucesso no projeto, responde: "Sucesso é entregar dentro prazo, no custo e dentro da qualidade aceitável que o cliente espera (requisitos do produto), gerando satisfação do cliente". Ou seja, basicamente o atendimento às questões técnicas do projeto constitui o sucesso sob a ótica desse gerente.

Durante a entrevista também foram identificados vários fatores que influenciam no sucesso de um projeto. Por exemplo:

a) Ter um sólido planejamento do projeto, ou seja, planos de projetos claramente definidos, com cronogramas realistas e com avaliação precisa dos riscos;

b) Ter competência na gestão de projetos com gerentes de projetos bem treinados e experientes. Para gerenciar um projeto 
é necessário ter conhecimento, mas não só conhecer a teoria ou normas e procedimentos, pois conhecimento isolado não funciona, tem que saber colocá-lo em prática;

c) A gestão de projetos exige habilidades tais como o relacionamento interpessoal (saber lidar com pessoas), habilidades na comunicação, capacidade na negociação, gerenciamento de conflitos e crises. Segundo esse gerente, em gestão de projetos "não adianta ser no grito";

d) É fundamental que os projetos estejam em linha com a estratégia de negócio;

e) Ter clareza nos requerimentos do projeto. Os objetivos claramente definidos, entendidos e validados para evitar, por exemplo, um scope creep (aumento de escopo). Quando isso ocorrer, seria importante ter um bom Change Management (Gestão da Mudança) em ação;

f) Apoio executivo, ou seja, ter um nível executivo que tenha poderes para tomar decisões e resolver problemas que possam surgir durante a execução do projeto;

g) Recursos e fundos financeiros estáveis. Caso ocorra cortes no orçamento do projeto, isto pode causar um dano irreversível à capacidade de entrega;

h) Ter metodologias e ferramentas de gestão de projetos.

Outros fatores também foram identificados e que têm relação com o sucesso de um projeto. O gerenciamento da comunicação foi apontado como crítico. Por exemplo, ao acompanhar a execução das entregas dos fornecedores, semanalmente, estes devem enviar o status do plano de suas entregas ao gerente de projeto. Isso ajuda a controlar e mitigar os possíveis riscos externos e que podem ser danosos ao projeto.

Por fim, o entrevistado ressalta que o uso de software para planejamento e controle é necessário do início ao término do projeto. Alguns projetos críticos, que podem ter seu prazo ou custo afetado, são acompanhados online via software de scorecard que informam de maneira clara e objetiva o status do projeto.

\section{Empresa $Y$}

A empresa $Y$ é uma multinacional que atua no segmento de energia e automação. A fábrica de Guarulhos é considerada uma 
das mais importantes. Essa unidade apresentou um faturamento da ordem de R\$ 1 bilhão de reais em 2011 (último dado disponível da planta), representando $50 \%$ do faturamento total do Brasil desse ano. Essa planta é responsável pela produção de transformadores, considerado seu produto carro-chefe. Em 2009, a unidade fabril de Guarulhos adotou a CCPM para gerenciamento de seus projetos. Antes disso, a empresa utilizava um sistema de gestão de projetos próprio e todo baseado em cronogramas.

Visando melhorar a produtividade de projetos da planta e utilizar um método mais eficiente de projetos, seus executivos decidiram pela adoção e implementação da CCPM para gestão de projetos. A empresa definiu alguns indicadores de metas apresentado na Tabela 3:

Tabela 3 - Metas após a implementação da CCPM na empresa $Y$

\begin{tabular}{lll}
\hline Indicador & Valor Atual & Meta \\
\hline Lucro Líquido & $9,5 \%$ da Receita Líquida & $20 \%$ da Receita Líquida \\
Entrega no prazo & $75 \%$ do total de pedidos & $95 \%$ do total de pedidos \\
Fluxo de Caixa Operacional & Negativo & Aumentar em $9 \%$ \\
Tempo do produto na fábrica & 4 meses & 2 a 3 meses \\
\hline
\end{tabular}

Fonte: Elaborado pelos autores

O projeto de implementação dessa nova metodologia (CCPM) duraram três anos. Seus gestores constataram que houve uma grande evolução com adoção da CCPM. Seu produto carro-chefe (transformadores) tiveram um aumento no faturamento na ordem de $25 \%$ e suas vendas aumentaram em $23 \%$ no mesmo período. Em 2011, 84\% dos transformadores foram entregues dentro do prazo. Anteriormente esse indicador era de 60\%. Houve diminuição do tempo de realização dos projetos de 26 dias para 13 dias. A empresa constatou também um aumento da satisfação e confiança dos clientes, gerando novos negócios e fidelizando a relação.

Nessa empresa foram identificados os fatores abaixo que levaram ao sucesso do projeto: 
a) Ter um objetivo claro com metas e indicadores de produtividade bem definidos;

b) Ter um método de gerenciamento de projeto (Best Practice). A CCPM já havia sido implantada em outras plantas e em outros países e se mostrou eficiente;

c) Trabalho em equipe. Antes da CCPM, o gerenciamento de projetos, bem como o conhecimento da ferramenta estavam centralizados em uma única pessoa que fazia o controle do projeto somente pelo cronograma;

d) A criação de uma área de macroplanejamento "PMO". Tendo a função de sincronizar a execução de todos os projetos, fazendo a alocação de recursos da melhor maneira possível;

e) Gestão tempo. Uma atividade só pode ser iniciada quando a atividade anterior estiver terminada e os recursos estiverem disponíveis;

f) Controle de projeto via dashboard ou fever chart (como é chamado na empresa). Foi avaliado que a criação de um dashboard de controle seria decisiva. Verde - o prazo será atendido; Amarelo - pode ocorrer um possível atraso; Vermelho - o projeto está atrasado.

g) Gerenciamento da comunicação. Realização de reuniões diárias para verificação das entregas, qualidade, riscos e melhorias para eliminar erros frequentes;

h) Resistência à mudança foi apontada como um fator de insucesso. Os colaboradores, que foram resistentes à implementação da nova cultura de gerenciamento de projetos, perderam seus empregos ou foram substituídos por novos colaboradores;

i) Tecnologia. Foi desenvolvido um software acessível aos envolvidos nos projetos que apresentava todo o andamento dos projetos. Isso ficava visível em todos os principais setores da fábrica;

j) Novo sistema de bonificação e prêmios gerou aumento de pró-atividade. Os prêmios passaram ser distribuídos considerando a finalização do projeto;

k) Alinhamento do negócio entre vendas, fábrica e engenharia; e

i) Treinamento. A empresa oferece treinamento visando passar as técnicas e desenvolver habilidade com a nova metodologia. 
A implementação CCPM como gerenciamento de projetos foi tão bem-sucedida, que ao passar a cumprir os prazos acordados com os clientes, isso acabou gerando "problemas" para os próprios clientes. Segundo o gerente de projeto, os clientes da empresa assumiam que ela não cumpriria os prazos acordados e que os atrasos seriam iminentes. Portanto, colocavam uma certa folga quanto ao recebimento. A partir do momento que a empresa $Y$ começou a entregar no prazo, os clientes não tinham como receber os transformadores, pois não tinham onde estocá-los. Esses produtos voltavam à empresa e ficavam aguardando os clientes se manifestarem.

\section{Empresa $Z$}

A empresa $Z$ é uma empresa brasileira e uma das maiores empresas do segmento aeroespaciais do mundo. Diante da necessidade de melhorar a entrega no prazo dos projetos, melhorar a produtividade e gestão de seu portfólio de produtos, entre 2009 e 2010 a empresa implementou a CCPM visando o gerenciamento de seus projetos. Seus gestores acreditavam que essa nova metodologia poderia significar uma vantagem competitiva em seu mercado de atuação. Entre os objetivos dessa implementação estavam: redução do tempo de execução dos projetos, aumentar a quantidade de projetos entregues e sem comprometer sua qualidade, entregar $100 \%$ dos projetos no prazo e melhorar a qualidade de vida dos envolvidos.

Após um ano de implementação da CCPM, foram constatados os seguintes resultados, observados na Tabela 4:

Tabela 4 - Ganhos após a implementação da CCPM na empresa Z

\begin{tabular}{llll}
\hline \multirow{2}{*}{ Departamento } & Março de 2010 & \multicolumn{2}{c}{ Março de } \\
& & 2011 & Variação \\
\hline Ciclo médio de execução dos projetos (dias) & 344 & 273 & $-21 \%$ \\
Produtividade do efetivo dedicado a projetos & 354 & 426 & $+20 \%$ \\
Ganhos Financeiros & - & - & $+24 \%$ \\
\hline
\end{tabular}

Fonte: Elaborado pelos autores 
Com base na entrevista com seu gerente de planejamento integrado e seu consultor interno de CCPM, foram identificados os seguintes fatores que podem influenciar o sucesso em projeto:

a) Planejamento. Uso de um método para a própria implementação de um método. O projeto foi divido em fases: iniciação, planejamento, execução e controle/monitoração;

b) Planejamento por cronograma. Formatar um cronograma com todas as tarefas que devem ser feitas. Anteriormente, a utilização dessa ferramenta por parte das pessoas não era comum e muito menos tinham essa crença;

c) Tecnologia 1. Uso de um software que simula a influência de uma determinada mudança nas prioridades de execução e entrada de novos projetos. Isso permitiria avaliar melhor os riscos e seus impactos;

d) Tecnologia 2. Desenvolvimento de um software para monitorar a execução dos projetos, status de atrasos, riscos e consumo do buffer;

e) Tecnologia 3. Desenvolvimento de um sistema de indicadores que pudessem ser acessados via web e integrar as tecnologias 1 e 2 na web;

g) Engajamento das partes interessadas (stakeholders). Foi verificado a importância da participação de todos os stakeholders, dentre eles, o apoio da alta direção. Pilares do sucesso: patrocínio, persistência e pessoas comprometidas com as iniciativas;

h) Auxílio de um Consultor especialista em CCPM na implementação do projeto;

i) Treinamento. Realização de workshops para as partes interessadas para que pudessem se familiarizar com as ferramentas e a metodologia.

\section{CONSIDERAÇões FINAIS}

Segundo Pinto e Slevin (1988), Ika (2009) e Shao, Müller e Turner (2012), a literatura que aborda os construtos "sucesso em projetos" e "fracasso em projetos" ainda não está consolidada quanto aos fatores que operacionalizam estes construtos. Para Ika (2009), a definição desses construtos representa um campo fértil de pesquisa que merece atenção dos pesquisadores. Alguns autores abordam 
esses construtos sob ótica das competências gerenciais; estrutura organizacional e tecnológica; práticas gerenciais e metodologias; questões técnicas (prazos, custos e escopo), envolvimento dos stakaholders e resultados auferidos (DE WIT, 1988; IKA, 2009; KEIL; MÄHRING, 2010; KENDRA; TAPLIN, 2004; MAHANEY; LEDERER, 2011; PINTO; SLEVIN, 1988; SHAO, MÜLLER; TURNER, 2012) que podem impactar em sucesso ou fracasso de projeto. Diante disso, esse trabalho teve como proposta identificar esses fatores através de uma pesquisa qualitativa exploratória por meio de entrevistas junto a seis executivos de três empresas de setores distintos (tecnologia da informação - empresa X; energia e automação - empresa Y; e aeroespacial - empresa Z). Duas dessas empresas implementaram a CCPM (empresa Y e Z) e uma o $P M B O K \circledR$ adaptado às suas necessidades e as melhores práticas de gestão no mundo (empresa $\mathrm{X}$ ). As três empresas são de grande porte com atuações globais e bastante reconhecidas no segmento em que atuam.

Com relação aos fatores de sucesso ou fracasso (quando não atendidas) em projetos, foi possível identificar, em todos os casos, os fatores que mais influenciaram os construtos. A Tabela 5 a seguir consolida os resultados observados.

Com base na Tabela 5, alguns fatores apontados pelos executivos e profissionais de projetos estão em consonância com os fatores mencionados na literatura sobre gerenciamento de projetos. Dentre os fatores mais importantes listados por esses profissionais que influenciam os construtos "sucesso em projeto" e/ou "fracasso em projeto" (se negligenciados pelas empresas) estão as competências gerenciais que foram manifestadas pelas dimensões: comunicação, habilidades gerenciais, atitudes, conhecimentos, gestão de mudança, gestão de pessoas, e engajamento dos stakeholders. O cumprimento das questões mais técnicas também foi citado como importante fator ao processo de atendimento ao planejado: gestão do tempo (prazos), gestão dos recursos financeiros e definição do escopo. Também emergiram as questões estruturais como fatores que corroboram com o sucesso ou fracasso (caso não seja levado em conta) em projeto: tecnologias e ferramentas, ter uma metodologia ajustada à organização, ter uma cultura de projeto e apoio da alta administração. Portanto, é possível inferir que uma vez observado a presença desses fatores, pode-se elevar a taxa de sucesso em projeto. 
Tabela 5 - Fatores que influenciam o sucesso ou fracasso nos projetos

\begin{tabular}{|c|c|c|c|c|}
\hline Variáveis & \multicolumn{3}{|c|}{ Empresas } & Referências \\
\hline & $X$ & $\mathrm{Y}$ & $Z$ & \\
\hline Planejamento & & & * & Cui, Zhao e Ravichandran (2011); Martin et al. (2007) \\
\hline Conhecimento & * & * & * & Lenfle e Loch (2010); Shepherd et al. (2011) \\
\hline Habilidades gerenciais & * & * & * & $\begin{array}{l}\text { Blackstone Jr, Cox III e Schleier Jr (2009); Mahaney e } \\
\text { Lederer (2009); Piyush, Dangayach e Mittal (2011) }\end{array}$ \\
\hline Atitudes & * & * & * & $\begin{array}{l}\text { Bendoly e Hur (2007); Blackstone Jr, Cox III e } \\
\text { Schleier Jr (2009); Mahaney e Lederer (2009); Piyush, } \\
\text { Dangayach e Mittal (2011) }\end{array}$ \\
\hline $\begin{array}{l}\text { Gestão de Recursos } \\
\text { Humanos }\end{array}$ & * & * & & $\begin{array}{l}\text { Mahaney e Lederer (2006), Piyush, Dangayach e } \\
\text { Mittal (2011) }\end{array}$ \\
\hline $\begin{array}{l}\text { Alinhamento } \\
\text { estratégico }\end{array}$ & * & * & & $\begin{array}{l}\text { Baker (2002), Dinsmore e Cooke-Davies (2006), } \\
\text { Marques Junior e Plonski (2011), Piyush, Dangayach } \\
\text { e Mittal (2011) }\end{array}$ \\
\hline Escopo bem definido & * & * & & $\begin{array}{l}\text { Aubry e Lièvre (2010), The Standish Group (2001, } \\
\text { 2009) Mahanev e Lederer (2006) Nokes e Kelly (2012) }\end{array}$ \\
\hline Gestão de mudança & * & & & Levasseur (2010), Mcmanus e Wood-Harper (2007) \\
\hline $\begin{array}{l}\text { Apoio da alta adminis- } \\
\text { tração }\end{array}$ & * & & & $\begin{array}{l}\text { Blackstone Jr, Cox III e Schleier Jr (2009), Keil e } \\
\text { Mähring (2010), Levasseur (2010), Nokes e Kelly (2012) }\end{array}$ \\
\hline $\begin{array}{l}\text { Gestão dos recursos } \\
\text { financeiros }\end{array}$ & * & & & $\begin{array}{l}\text { Balderstone e Mabin (1998), Keil e Mähring (2010), } \\
\text { Mabin e Balderstone (2003), Mahaney e Lederer (2006) }\end{array}$ \\
\hline Tecnologias e ferra- & * & * & * & Kendra e Taplin (2004) \\
\hline $\begin{array}{l}\text { mentas } \\
\text { Ter uma metodologia }\end{array}$ & * & * & * & Aubry e Lièvre (2010), Bouer e Carvalho (2005) \\
\hline $\begin{array}{l}\text { ajustada à organização } \\
\text { Project Management }\end{array}$ & & * & * & Kendra e Taplin (2004) \\
\hline $\begin{array}{l}\text { Office (PMO) } \\
\text { Gestão do tempo } \\
\text { (prazos) }\end{array}$ & * & * & & $\begin{array}{l}\text { Aubry e Lièvre (2010), The Standish Group (2001, } \\
\text { 2009), Mahaney e Lederer (2006), Shao, Müller e } \\
\text { Turner (2012) }\end{array}$ \\
\hline $\begin{array}{l}\text { Gestão da } \\
\text { comunicação }\end{array}$ & * & * & & $\begin{array}{l}\text { Blackstone Jr, Cox III e Schleier Jr (2009), Ding e } \\
\text { Ding (2008), Henderson (2008) }\end{array}$ \\
\hline $\begin{array}{l}\text { Ter uma cultura e } \\
\text { projeto } \\
\text { Incentivo/ Prêmio }\end{array}$ & * & * & & Nokes e Kélly (2012) \\
\hline $\begin{array}{l}\text { Engajamento partes in- } \\
\text { teressadas (stakeholders) }\end{array}$ & & & * & $\begin{array}{l}\text { Blackstone Jr, Cox III e Schleier Jr (2009), Keil e Mähring } \\
\text { (2010), Levasseur (2010), Lim e Mohamed (1999) }\end{array}$ \\
\hline $\begin{array}{l}\text { Treinamento na meto- } \\
\text { dologia }\end{array}$ & * & * & * & Aubry e Lièvre (2010) \\
\hline Gestão da qualidade & * & & & $\begin{array}{l}\text { Aubry e Lièvre (2010), The Standish Group (2001, } \\
\text { 2009), Ika (2009), Mahaney e Lederer (2006), Shao, } \\
\text { Müller e Turner (2012) }\end{array}$ \\
\hline Satisfação do cliente & * & & & $\begin{array}{l}\text { Blackstone Jr, Cox III e Schleier Jr (2009), De Wit } \\
\text { (1988), Henderson (2008), Keil e Mähring (2010), } \\
\text { Levasseur (2010), Nokes e Kelly (2012) }\end{array}$ \\
\hline
\end{tabular}

Fonte: Elaborado pelos autores 
Considerando as limitações desta pesquisa, o trabalho teve como foco analisar apenas duas metodologias utilizadas em gestão de projetos. Outra limitação foi o número reduzido de empresas o que não permite generalizar os resultados para outros segmentos. Como sugestão para projetos futuros, seria estender essa pesquisa qualitativa considerando outras metodologias não cobertas nesta investigação e/ ou realizar uma survey visando avaliar os fatores apresentados neste estudo de forma quantitativa.

\section{REFERÊNCIAS}

AJZEN, I.; FISHBEIN, M. Understanding attitudes and predicting social behavior. Englewood Cliffs: Prentice Hall, 1980.

ALAMI, A. Why Do Information Technology Projects Fail? Procedia Computer Science, v. 100, p. 62-71, 2016.

ALENCAR, E. Introdução à metodologia de pesquisa social. Lavras: UFLA/FAEPE, 2000.

AUBRY, M.; LIÈVRE, P. Ambidexterity as a Competence of Project Leaders: A Case Study From Two Polar Expeditions. Project Management Journal, v. 41, n. 3, p. 32-44, 2010.

BACCARINI, D. The Logical Framework Method for Defining Project Success. Project Management Journal, v. 30, n. 4, p. 25-32, 1999.

BAKER, B. The Fall of the Firefly: An Assessment of a Failed Project Strategy. Project Management Journal, v. 33, n. 3, p. 53-57, 2002.

BAKER, B. N.; MURPHY, D. C.; FISHER, D. Factors affecting project success. In: KING, C. \& W. R. (Ed.). . Project management handbook. New York: Van Nostrand Reinhold, 2008. p. 902-919.

BALDERSTONE, S. J.; MABIN, V. J. A Review of Goldratt's Theory of Constraints (TOC) - lessons from the international literature. Operational Research Society of New Zealand 33rd Annual Conference. Anais...Auckland: 1998

BARNEY, J. Firm resources and sustained competitive advantage. Journal of management, v. 17 , n. 1, p. 99-120, 1991.

BARNEY, J. B. Is the Resource-Based “View” a Useful Perspective for Strategic Management Research? Yes. The Academy of Management Review, v. 26, n. 1, p. 41-56, 2001.

BARNEY, J. B.; WRIGHT, P. M. On becoming a strategic partner: The role of human resources in gaining competitive advantage. Human Resource Management, v. 37, n. 1, p. 31-46, jan. 1998.

BELOUT, A. Effects of human resource management on project effectiveness and success: Toward a new conceptual framework. International Journal of Project Management, v. 16, n. 1, p. 21-26, fev. 1998. 
BENDOLY, E.; DONOHUE, K.; SCHULTZ, K. L. Behavior in operations management: Assessing recent findings and revisiting old assumptions. Journal of Operations Management, v. 24, n. 6, p. 737-752, dez. 2006.

BENDOLY, E.; HUR, D. Bipolarity in reactions to operational 'constraints': OM bugs under an OB lens. Journal of Operations Management, v. 25, n. 1, p. 1-13, jan. 2007.

BLACKSTONE JR, J. H.; COX III, J. F.; SCHLEIER JR, J. G. A tutorial on project management from a theory of constraints perspective. International Journal of Production Research, v. 47, n. 24, p. 7029-7046, 15 dez. 2009.

BOUER, R.; CARVALHO, M. M. Metodologia singular de gestão de projetos: condição suficiente para a maturidade em gestão de projetos? Revista Produção, v. 15, n. 3, p. 347-361, 2005.

COATES, T. T.; MCDERMOTT, C. M. An exploratory analysis of new competencies: a resource based view perspective. Journal of Operations Management, v. 20, n. 5, p. 435-450, set. 2002.

COOPER, D. R.; SCHINDLER, P. S. Métodos de Pesquisa em Administração. 10. ed. ed. Porto Alegre: Bookman, 2011.

CRAWFORD, L. Developing Organizational Project Management Capability: Theory and Practice. Project Management Journal, v. 36, n. 3, p. 74-97, 2006.

CRAWFORD, L.; HOBBS, B.; TURNER, J. R. Aligning Capability with Strategy: Categorizing Projects to Do The Right Projects and to Do Them Right. Project Management Journal, v. 37, n. 2, p. 38-50, 2006.

CRUZ, C. E.; SCUR, G.; CARVALHO, M. M. DE. Success dimensions analysis in capital goods projects: an approach exploring the soft and hard perspective in projects. Revista Gestão da Produção Operações e Sistemas, v. 13, p. 77-100, 2018.

CUI, A. S.; ZHAO, M.; RAVICHANDRAN, T. Market Uncertainty and Dynamic New Product Launch Strategies: A System Dynamics Model. IEEE Transactions on Engineering Management, v. 58, n. 3, p. 530-550, ago. 2011.

DE WIT, A. Measurement of project success. International Journal of Project Management, v. 6, n. 3, p. 164-170, ago. 1988.

DING, H.; DING, X. Project Management, Critical Praxis, and Process-Oriented Approach to Teamwork. Business Communication Quarterly, v. 71, n. 4, p. 456-471, 16 jul. 2008.

DINSMORE, P. C.; COOKE-DAVIES, T. J. Right Projects Done Right: From Business Strategy to Successful Project Implementation. San Francisco: Jossey-Bass, 2006.

EISENHARDT, K. M.; MARTIN, J. A. Dynamic capabilities: what are they? Strategic Management Journal, v. 21, n. 10-11, p. 1105-1121, out. 2000.

ENGWALL, M. No project is an island: linking projects to history and context. Research Policy, v. 32, n. 5, p. 789-808, 2003.

FERN, E.; ZAREI-KESHEH, M. Tratado de medidas confiáveis de conclusão (CCMT). Revista Mundo Project Management, v. 38, n. Abril-Maio, p. 52-53, 2011.

FISHBEIN, M.; AJZEN, I. Belief, attitude, intention, and behavior: an introduction to theory and research. Philippines: Addison-Wesley, 1975. 
FISHBEIN, M.; MIDDLESTADT, S. Noncognitive Effects on Attitude Formation and Change: Fact or Artifact? Journal of Consumer Psychology, v. 4, n. 2, p. 181-202, jan. 1995.

FROEHLE, C. M.; ROTH, A. V. New measurement scales for evaluating perceptions of the technology-mediated customer service experience. Journal of Operations Management, v. 22, n. 1, p. 1-21, fev. 2004.

GERALDI, J. G.; LEE-KELLEY, L.; KUTSCH, E. The Titanic sunk, so what? Project manager response to unexpected events. International Journal of Project Management, v. 28, n. 6, p. 547-558, ago. 2010.

GHEMAWAT, P.; RIVKIN, J. W. Creating Competitive Advantage. Harvard Business Review, n. February, p. 1-21, 2006.

GOLDRATT, E. M. Critical Chain: A Business Novel. Croton-on-Hudson: The North River Press, 1997.

GOLDRATT, E. M.; COX, J. A Meta. 4. ed. rev ed. São Paulo: Claudiney Fullmann, 1990.

GOLDRATT, E. M.; FOX, R. E. The race. Croton-on-Hudson: The North River Press, 1986.

HAIR, J. F. et al. Fundamentos de Métodos de Pesquisa em Administração. Porto Alegre: Bookman, 2005.

HELFAT, C. E.; PETERAF, M. A. The Dynamic Resource-Based View: Capability Lifecycles. Strategic Management Journal, v. 24, n. 10, p. 997-1010, 2003.

HENDERSON, L. S. The Impact of Project Managers' Communication Competencies: Validation and Extension of a Research Model for Virtuality, Satisfaction, and Productivity on Project Teams. Project Management Journal, v. 39, n. 2, p. 48-59, 2008.

HERROELEN, W.; LEUS, R. On the merits and pitfalls of critical chain scheduling. Journal of Operations Management, v. 19, n. 5, p. 559-577, 2001.

HUESMANN, L. R.; GUERRA, N. G. Children's normative beliefs about aggression and aggressive behavior. Journal of Personality and Social Psychology, v. 72, n. 2, p. 408-419, 1997.

HUSSAIN, A.; MKPOJIOGU, E. Requirements: Towards an understanding on why software projects fail. Proceedings of the International Conference on Applied Science and Technology (Icast'16). Anais...12 August, Kedah, Malaysia: 2016

HYEJUNG, L. E. E.; PARK, J.-G.; JUNGWOO, L. E. E. Role of Leadership Competencies and Team Social Capital in it Services. Journal of Computer Information Systems, v. 53, n. 4, p. 1-11, 2013.

IKA, L. A. Project Success as a Topic in Project Management Journals. Project Management Journal, v. 40, n. 4, p. 6-19, 2009.

JUGDEV, K. Through the Looking Glass: Examining Theory Development in Project Management With the Resource-Based View Lens. Project Management Journal, v. 35, n. 3, p. 15-26, 2004.

JUGDEV, K.; MATHUR, G.; FUNG, T. S. Project management assets and their relationship with the project management capability of the firm. International Journal of Project Management, v. 25, n. 6, p. 560-568, ago. 2007. 
KEIL, M.; MÄHRING, M. Is Your Project Turning into a Black Hole? California Management Review, v. 53, n. 1, p. 6-31, nov. 2010.

KENDRA, K.; TAPLIN, L. J. Project Success: A Cultural Framework. Project Management Journal, v. 35, n. 1, p. 30-45, 2004.

KERZNER, H. Project management metrics, KPIs, and dashboards: a guide to measuring and monitoring project performance. 1st. ed. New Jersey: John Wiley \& Sons, 2011.

KIM, S.; MABIN, V. J.; DAVIES, J. The theory of constraints thinking processes: retrospect and prospect. International Journal of Operations \& Production Management, v. 28, n. 2, p. 155-184, 2008.

KRIPPENDORFF, K. Content Analysis: An Introduction to Its Methodology. 3rd ed. ed. Los Angeles, CA: Sage Publications, 2012.

LEACH, L. P. Critical chain project management improves project performance. Project Management Journal, v. 30, n. 2, p. 39-51, 1999.

LENFLE, S.; LOCH, C. Lost Roots: How Project Management Came to Emphasize Control Over Flexibility and Novelty. California Management Review, v. 53, n. 1, p. 32-55, 2010.

LEVASSEUR, R. E. People Skills: Ensuring Project Success--A Change Management Perspective. Interfaces, v. 40, n. 2, p. 159-162, 13 abr. 2010.

LIM, C. S.; MOHAMED, M. Z. Criteria of project success: an exploratory re-examination. International Journal of Project Management, v. 17, n. 4, p. 243-248, ago. 1999.

LOVE, P. E. D. et al. Causal Discovery and Inference of Project Disputes. IEEE Transactions on Engineering Management, v. 58, n. 3, p. 400-411, 2011.

MABIN, V. J.; BALDERSTONE, S. J. The performance of the theory of constraints methodology: Analysis and discussion of successful TOC applications. International Journal of Operations \& Production Management, v. 23, n. 5-6, p. 568-595, 2003.

MAHANEY, R. C.; LEDERER, A. L. The Effect of Intrinsic and Extrinsic Rewards For Developers on Information Systems Project Success. Project Management Journal, v. 37, n. 4, p. 42-54, 2006.

MAHANEY, R. C.; LEDERER, A. L. An Agency Theory Explanation of Project Success. Journal of Computer Information Systems, v. 51, n. 4, p. 102-113, 2011.

MARQUES JUNIOR, L. J.; PLONSKI, G. A. Gestão de projetos em empresas no Brasil : abordagem "tamanho único"? Gestão \& Produção, v. 18, n. 1, p. 1-12, 2011.

MARTIN, N. L.; PEARSON, J. M.; FURUMO, K. IS Project Management: Size, Practices and the Project Management Office. Journal of Computer Information Systems, v. 47, n. 4, p. 52-60, 2007.

MARZAGÃO, D. S. L.; CARVALHO, M. M. DE. The influence of project leaders' behavioral competencies on the performance of Six Sigma projects. Review of Business Management, v. 18, n. 62, p. 609-632, 2016.

MAZUR, A. et al. Rating defence major project success: The role of personal attributes and stakeholder relationships. International Journal of Project Management, v. 32, n. 6, p. 944-957, 1 ago. 2014. 
MCMANUS, J.; WOOD-HARPER, T. Understanding the Sources of Information Systems Project Failure. Management Services, v. 51, n. 3, p. 38-43, 2007.

MIKAELIAN, T. et al. Real Options in Enterprise Architecture: A Holistic Mapping of Mechanisms and Types for Uncertainty Management. IEEE Transactions on Engineering Management, v. 58, n. 3, p. 457-470, 2011.

MILES, M. B.; HUBERMAN, A. M. Qualitative data analysis: an expanded sourcebook. 2nd ed. ed. California, USA: Sage Publications, 1994.

MOURA, R. L. DE; CARNEIRO, T. C. J.; FREITAS, E. R. Condicionantes de sucesso em projetos de software e sua influência nos resultados. Revista Gestão \& Tecnologia, v. 18, n. 1, p. 61-87, 2018.

MOURÃO, I. P. B. Implantação da metodologia da corrente crítica. IETEC - Instituto de Educação Tecnológica, p. 4, 2007.

MOUTINHO, K.; ROAZZI, A. As teorias da ação racional e da ação planejada: Relações entre intenções e comportamentos. Avaliação Psicológica, v. 9, n. 2, p. 279-287, 2010.

MUKERJEE, H. S.; PRASAD, U. D. Definitions of Project Success in Implementation of Customer Relationship Management (CRM) Information Technology (IT) Solutions: Perspectives of Consultants from India. South Asian Journal of Management, v. 24, n. 4, p. 142-157, out. 2017.

NOKES, S.; KELLY, S. O Guia Definitivo do Gerenciamento de Projetos: Como Alcançar Resultados dentro do Prazo e do Orçamento. $2^{\text {a }}$ ed. Porto Alegre: Bookman, 2012.

PEDROSA, A. J. P.; CARVALHO, F. M. Análise dos fundamentos da teoria baseada nos recursos. Revista Ibero-Americana de Estratégia, v. 13, n. 02, p. 10-24, 2014.

PENG, D. X.; SCHROEDER, R. G.; SHAH, R. Linking routines to operations capabilities: A new perspective. Journal of Operations Management, v. 26, n. 6, p. 730-748, nov. 2008.

PENROSE, E. The Theory of the Growth of the Firm. Fourth edi ed. New York: Oxford University Press, 1959.

PETERAF, M. A. The cornerstones of competitive advantage: a resource-based view. Strategic Management Journal, v. 14, n. April, p. 179-191, 1993.

PINTO, J. K.; SLEVIN, D. P. Project Success: Definitions and Measurement Techniques. Project Management Journal, v. 19, n. 1, p. 67-72, 1988.

PIYUSH, M.; DANGAYACH, G. S.; MITTAL, M. L. A Study of Critical Project Success Parameters in Different Organizational Conditions. Advances in Management, v. 4, n. 8, p. 50-56, 2011.

PMI. Um Guia do Conhecimento em gerenciamento de projetos (Guia PMBOK ). 4ed. ed. Newtown Square: Project Management Institute, 2008.

RAHMAN, S. Theory of constraints. International Journal of Operations \& Production Management, v. 18, n. 4, p. 336-355, 1998.

RAHMAN, S. The theory of constraints' thinking process approach to developing strategies in supply chains. International Journal of Physical Distribution \& Logistics Management, v. 32, n. 10, p. 809-828, 2002. 
RAY, G.; BARNEY, J. B.; MUHANNA, W. A. Capabilities , Business Processes, and Competitive Advantage : Choosing the Dependent Variable in Empirical Tests of the Resource-Based View. Strategic Management Journal, v. 25, n. 1, p. 23-37, 2004.

RAZ, T.; BARNES, R.; DVIR, D. A critical look at critical chain project management. Project Management Journal, v. 34, n. 4, p. 24-32, 2003.

ROBERTSON, S.; WILLIAMS, T. Understanding Project Failure: Using Cognitive Mapping in an Insurance Project. Project Management Journal, v. 37, n. 4, p. 55-71, 2006.

SAVAGE, S.; HILTON, J.; THIBAULT, M. O problema das médias no gerenciamento de projetos. Revista Mundo Project Management, v. 38, n. Abril-Maio, p. 10-19, 2011.

SCHELINI, A. L. S.; MARTENS, C. D. P.; PISCOPO, M. R. Project management as a competitive advantage for the internationalization of Brazilian companies. Internext, v. 12, n. 3, p. 1-15, 2017.

SCHOENHERR, T. et al. Competitive Capabilities among Manufacturing Plants in Developing, Emerging, and Industrialized Countries: A Comparative Analysis. Decision Sciences, v. 43, n. 1, p. 37-71, 2012.

SERRADOR, P.; GEMINO, A.; REICH, B. H. Creating a Climate for Project Success. The Journal of Modern Project Management, v. 6, n. 1, p. 38-47, 2018.

SHAHHOSSEIN, V.; AFSHAR, M. R.; AMIRI, O. The Root Causes of Construction Project Failure. Scientia Iranica, v. 25, n. 1, p. 93-108, 2017.

SHAO, J.; MÜLLER, R.; TURNER, J. R. Measuring Program Success. Project Management Journal, v. 43, n. 1, p. 37-49, 2012.

SHEPHERD, D. A.; PATZELT, H.; WOLFE, M. Moving Forward From Project Failure: Negative Emotions, Affective Commitment, and Learning From the Experience. Academy of Management Journal, v. 54, n. 6, p. 1229-1259, 1 dez. 2011.

STRATTON, R. Critical Chain Project Management Theory and Practice. POMS 20th Annual Conference. Anais...Orlando, Florida U.S.A.: 2009

TEECE, D. J.; PISANO, G.; SHUEN, A. Dynamic Capabilities and Strategic Management. Strategic Management Journal, v. 18, n. 7, p. 509-533, 1997.

THE STANDISH GROUP. Chaos Report, 2001.

THE STANDISH GROUP. Chaos Report, 2009.

TREJO, A. Emotional Intelligence and Project Outcomes in Technology. International Management Review, v. 10, n. 1, p. 31-42, 2014.

TRIVIÑOS, A. N. S. Introdução à Pesquisa em Ciências Sociais: a Pesquisa Qualitativa em Educação. São Paulo: Atlas, 1987.

VAN DE VEN, A. H. Nothing is as practical as a good theory. Academy of Management Review, v. 14, n. 4, p. 486-489, ago. 1989.

VIEIRA, A. M.; RIVERA, D. P. B. A Hermenêutica no Campo Organizacional: duas possibilidades interpretativistas de pesquisa. Revista Brasileira de Gestão de Negócios, v. 14, n. 44, p. 261-273, 2012. 
WACKER, J. G. A definition of theory: research guidelines for different theory-building research methods in operations management. Journal of Operations Management, v. 16, n. 4, p. 361-385, jul. 1998.

WATSON, K. J.; BLACKSTONE, J. H.; GARDINER, S. C. The evolution of a management philosophy: The theory of constraints. Journal of Operations Management, v. 25, n. 2, p. 387-402, mar. 2007.

WERNERFELT, B. A Resource-based View of the Firm. Strategic Management Journal, v. 5, n. 2, p. 171-180, 1984.

ZHANG, L.; FAN, W. Improving performance of construction projects. Engineering, Construction and Architectural Management, v. 20, n. 2, p. 195-207, 22 fev. 2013.

Recebido em: 17-5-2018

Aprovado em: 1-6-2019

Avaliado pelo sistema double blind review.

Disponível em http://mjs.metodista.br/index.php/roc 